\title{
Implementation of Online Hospitals and Factors Influencing the Adoption of Mobile Medical Services in China: Cross-Sectional Survey Study
}

Huanlin Wang, MSc; LanYu Liang, MCM; ChunLin Du, MSc; YongKang Wu, MD

West China Hospital, Sichuan University, Sichuan, China

\section{Corresponding Author:}

YongKang $\mathrm{Wu}, \mathrm{MD}$

West China Hospital

Sichuan University

No. 37 Guoxue Lane

Wuhou District

Sichuan

China

Phone: 862885423265

Email: vipwyk@163.com

\section{Abstract}

Background: Online hospitals are part of an innovative model that allows China to explore telemedicine services based on national conditions with large populations, uneven distribution of medical resources, and lack of quality medical resources, especially among residents needing to be protected from COVID-19 infection.

Objective: In this study, we built a hypothesis model based on the Unified Theory of Acceptance and Use of Technology (UTAUT) in order to analyze the factors that may influence patients' willingness to use mobile medical services. This research was designed to assist in the development of mobile medical services. Residents who do not live in urban areas and cannot access medical assistance would greatly benefit from this research, as they could immediately go to the online hospital when needed.

Methods: A cross-sectional study based at the West China Hospital, Sichuan University, was conducted in July 2020. A total of 407 respondents, 18 to 59 years old, in Western China were recruited by convenience sampling. We also conducted an empirical test for the hypothesis model and applied structural equation modeling to estimate the significance of path coefficients so that we could better understand the influencing factors.

Results: Out of 407 respondents, $95(23.3 \%)$ were aware of online hospitals, while $312(76.7 \%)$ indicated that they have never heard of online hospitals before. Gender $(P=.048)$ and education level $(P=.04)$ affected people's willingness to use online hospitals, and both of these factors promoted the use of online hospitals (odds ratio [OR] 2.844, 95\% CI 1.010-8.003, and OR 2.187, 95\% CI 1.031-4.636, respectively). According to structural equation modeling, the results of the path coefficient analysis indicated that performance expectancy, effort expectancy, and facilitating conditions have positive effects on patients' willingness to use online hospitals.

Conclusions: The goal of our research was to determine the factors that influence patients' awareness and willingness to use online hospitals. Currently, the public's awareness and usage of online hospitals is low. In fact, effort expectancy was the most important factor that influenced the use of online hospitals; being female and having a high education also played positive roles toward the use of mobile medical services.

(JMIR Mhealth Uhealth 2021;9(2):e25960) doi: $\underline{10.2196 / 25960}$

\section{KEYWORDS}

COVID-19; online hospital; mobile medical service; Unified Theory of Acceptance and Use of Technology; UTAUT 


\section{Introduction}

\section{Background}

With the advent of the internet plus era, information technology (IT) has brought great convenience to people's production and lives. At the same time, it has provided new ideas for medical service reform, and remote, mobile medical services have emerged [1]. As the largest developing country, China has a large population, an aging population, uneven distribution of medical resources, and lack of high-quality medical resources. Faced with increasing demand for medical and health services, around the year 2000, the Chinese government actively explored the application of internet IT to carry out innovative diagnoses and treatments based on the conditions seen nationwide. In this context, online hospitals have appeared, along with the emergence and spread of COVID-19, and were vigorously promoted to divert patients from hospitals and to reduce the risk of cross-infection in hospitals. The operation of online hospitals relies on offline physical medical institutions to provide patients with online follow-up services for common and chronic diseases through devices connected to the internet. Patients use mobile terminals to communicate with doctors online in the form of pictures, texts, voice messages, or videos [2]. Studies have shown that mobile medical services need to consider the public's acceptance of these services; more attention should be paid to public awareness and experience during the adoption process in order to increase willingness to adopt services and increase utilization of services by users [3]. For one thing, online hospitals in China have just started to be implemented; as a result, some patients have little understanding of online hospitals. In addition, because of their traditional medical thinking, some patients have misunderstandings that lead them to believe that online hospitals are not reliable. Whether mobile medical services can be popularized and applied has become the focus of current research [4,5]. In order to explore patients' willingness to use mobile medical services and their influencing factors, this study examines Chinese patients' perspectives of online hospitals and builds a model of their willingness to use these services, based on the Unified Theory of Acceptance and Use of Technology. In this study, we discuss patients' willingness to use mobile medical services of online hospitals and their influencing factors in order to provide strong evidence for the study of patients' acceptance behavior of mobile medical services; in addition, using mobile medical methods to provide online diagnoses and treatment services for common and chronic diseases can be a reference point and offer suggestions for the global response to the COVID-19 outbreak.

\section{Literature Review and Hypotheses Development}

In the field of IT, users' technology adoption behavior has always attracted much attention. There are many models and theories that can be used to study user behavior, such as the technology acceptance model, the rational behavior theory, the planned behavior theory, and the UTAUT. The UTAUT is a self-rational action theory based on the technology acceptance model by Venkatesh and Davis and others [6,7]. This model is based on four structures: performance expectation, effort expectation, social influence, and convenience to explain the intention and behavior of individuals using technology [7]. Existing literature studies have shown that the UTAUT model provides better and more complete explanations about users' technology adoption behavior than other technology acceptance models. This model not only promotes previous research results but it retains their simple structure. Therefore, it currently has the best predictive ability $[8,9]$. This model has been widely used in different fields of medical care. Research has confirmed that the UTAUT model is also acceptable in the field of health care mobile technology [10]. Phichitchaisopa and Naenna found that factors such as effort expectation, performance expectation, and facilitating conditions have a significant impact on the adoption of mobile health [11]. Cimperman et al used the UTAUT model to study mobile health factors in the elderly. They also found that performance expectation, effort expectation, social influence, technical anxiety, and other factors had a significant impact on users' behavioral intentions [12]. Most of the relevant research in the field of mobile health, by both domestic and foreign scholars, focuses on product functions and use effects of mobile medical equipment and mobile health apps [13,14]; however, we have found no research on the willingness to use mobile online medical services. Moreover, mobile medical services of online hospitals are different from other mobile health care support applications. In their initial stage of promotion and operation, we should pay attention to the public's expectations of, and willingness to use, these services $[15,16]$. Through the extension and application of the UTAUT model, we aim to determine the factors influencing willingness to use these services and the relationship between them; our research will fill this gap in the field of mobile medicine.

\section{Hypothetical Model Construction}

Due to the special attributes of telemedicine, there will be some risk factors in the use process; for example, the mobile medical platform uploads patient information to the information system, patients and doctors need to communicate in a virtual environment, etc. The way these risks are perceived by the patient will affect their willingness to use the mobile medical platform [17]. Based on this and on the information system selected to adopt the UTAUT model, the perceived risk variable was added, which was used to analyze the patients' perception of the risk of diagnosis and treatment via the internet. Finally, the hypothesis regarding patients' willingness to accept medical treatment from online hospitals was formed. This study is based on the scales that have been researched and applied by scholars, both domestic and foreign, combined with the participation by online hospital patients. Through induction and summary, we have defined the model variables; the measurement items and model construction of each research variable in the model have also been proposed, as seen in Table 1 [18-27]. 
Table 1. Construct definitions and model assumptions.

\begin{tabular}{|c|c|c|c|}
\hline Model variable & Definition & Model assumptions & References \\
\hline Performance expectancy & $\begin{array}{l}\text { Refers to the patients' judgment of the } \\
\text { benefit of mobile medical services }\end{array}$ & $\begin{array}{l}\text { Performance expectancy has a positive impact } \\
\text { on the patients' willingness to use online hos- } \\
\text { pitals }\end{array}$ & $\begin{array}{l}\text { Venkatesh et al [18] } \\
\text { Hoque and Sorwar [19] } \\
\text { Hoque et al [20] }\end{array}$ \\
\hline Effort expectancy & $\begin{array}{l}\text { Refers to the patients' judgment of the ease } \\
\text { of acceptance and use of mobile medical } \\
\text { services }\end{array}$ & $\begin{array}{l}\text { Effort expectancy has a positive impact on the } \\
\text { patients' willingness to use online hospitals }\end{array}$ & $\begin{array}{l}\text { Xue et al [21] } \\
\text { Alalwan et al [22] } \\
\text { Shareef et al [23] }\end{array}$ \\
\hline Social influence & $\begin{array}{l}\text { Refers to the external influence that patients } \\
\text { perceive when using the online hospital app }\end{array}$ & $\begin{array}{l}\text { Social influence has a positive impact on the } \\
\text { patients' willingness to use online hospitals }\end{array}$ & $\begin{array}{l}\text { Nguyen et al [24] } \\
\text { Hoque and Sorwar [19] }\end{array}$ \\
\hline Perceived risk & $\begin{array}{l}\text { Refers to the patients' perception of possible } \\
\text { adverse consequences through online hospi- } \\
\text { tal visits }\end{array}$ & $\begin{array}{l}\text { Perceived risk has a negative impact on the } \\
\text { patients' willingness to use online hospitals }\end{array}$ & $\begin{array}{l}\text { Kim and Park [25] } \\
\text { Hsieh [26] }\end{array}$ \\
\hline Facilitating conditions & $\begin{array}{l}\text { Refers to whether the existing online hospi- } \\
\text { tal platform, technology, service-supporting } \\
\text { measures, and personal equipment are suffi- } \\
\text { cient to support mobile medical services }\end{array}$ & $\begin{array}{l}\text { Facilitating conditions have a positive impact } \\
\text { on the patients' willingness to use online hos- } \\
\text { pitals }\end{array}$ & Cilliers et al [27] \\
\hline
\end{tabular}

\section{Methods}

\section{Participants}

The average number of daily outpatients at the West China Hospital, Sichuan University, is about 16,000. Based on the fact that crowd gathering should be avoided during the COVID-19 pandemic, and considering the low awareness and utilization rates of online hospitals, the research team used convenience sampling to recruit survey subjects. Recruitment began on July 4, 2020, when questionnaires were distributed by specially trained investigators at the nurse stations of the West China Hospital, Sichuan University. The target group participants filled out the paper questionnaire on a voluntary basis or filled out the electronic questionnaire by scanning the code on their mobile phones. The questionnaires were answered anonymously and were collected on the spot. Inclusion criteria for participants included the following: (1) were between 18 and 59 years old; (2) were able to fill out the questionnaire independently, with clear consciousness and no obvious cognitive impairment; and (3) volunteered to participate in this study. Exclusion criteria included the following: (1) had a mental disorder and could not communicate normally and (2) refused to participate in this investigation.

\section{Design and Material}

This is a cross-sectional study investigating patients' willingness to use an online hospital platform. The research setting was a large general hospital in Western China. Internet diagnosis and treatment services involved in this study are closely related to internet use. A previous survey about online hospital participation by the elderly administered by our team found that most elderly people were not proficient in using mobile phone apps and had some difficulties operating mobile phones; the children of most of these participants helped them operate mobile phones and use the apps Therefore, this survey was mainly aimed at a sample of young and middle-aged participants.

\section{Procedure}

Using the questionnaire survey method, the researchers designed their own questionnaires under the guidance of experts based on the UTAUT model, combined with the characteristics of online hospital operations. To ensure the validity of the questionnaire content, all measurement items were modified based on relevant domestic and foreign documents; see Multimedia Appendix 1 for details. The questionnaire used a 5-point Likert scale, ranging from 1 (completely disagree) to 5 (completely agree); the respondents chose the options that best suited their actual situations. Before the formal issuance of the questionnaire, the researchers conducted a presurvey; they selected 20 patients for the presurvey, modified the items in the questionnaire that were difficult to understand, and generated ambiguity. Finally, 31 of the most representative items of the questionnaire were selected. The data were collected from completed questionnaires and sorted using EpiData, version 3.1 (EpiData Association); the questionnaire data were statistically analyzed using SPSS Statistics for Macintosh, version 24.0 (IBM Corp), and SPSS Amos, version 24.0 (IBM Corp). The statistical methods were verified by descriptive analysis, reliability and validity tests, analysis of variance, and structural equation modeling, as needed.

\section{Results}

\section{General Statistical Description}

In this study, a total of 412 questionnaires were collected, of which 407 were valid, with an effective rate of $98.8 \%$. The ratio of men to women in the survey was $1: 1.19$, including 319 young people out of 407 participants $(78.4 \%)$ and 88 middle-aged people (21.6\%). Among the survey respondents, $23.3 \%$ (95/407) knew about online hospitals, while $76.7 \%$ (312/407) said they did not know about, or had not heard of, online hospitals. A total of $95.3 \%(388 / 407)$ of the respondents expressed their support for, and had acceptable attitudes toward, the internet diagnosis and treatment model after being introduced to it by the researchers; see Table 2 for details. 
Table 2. Participants characteristics.

\begin{tabular}{|c|c|}
\hline Characteristic & Value (N=407), n (\%) \\
\hline \multicolumn{2}{|l|}{ Gender } \\
\hline Male & $186(45.7)$ \\
\hline Female & $221(54.3)$ \\
\hline \multicolumn{2}{|l|}{ Age (years) } \\
\hline $18-44$ & $319(78.4)$ \\
\hline $45-59$ & 88 (21.6) \\
\hline \multicolumn{2}{|l|}{ Education level } \\
\hline Less than high school & $16(3.9)$ \\
\hline High school graduate & $98(24.1)$ \\
\hline Bachelor's degree & $193(47.4)$ \\
\hline Master's or doctoral degree & $100(24.6)$ \\
\hline \multicolumn{2}{|l|}{ Professional background } \\
\hline Official & $131(32.2)$ \\
\hline Company employee & $137(33.7)$ \\
\hline Migrant worker & $10(2.5)$ \\
\hline Farmer & $7(1.7)$ \\
\hline Other & $122(30.0)$ \\
\hline \multicolumn{2}{|c|}{ Monthly income (RMB; US \$1=RMB 6.4790) } \\
\hline $0-2000$ & $40(9.8)$ \\
\hline $2001-5000$ & $114(28.0)$ \\
\hline $5001-8000$ & $127(31.2)$ \\
\hline $8001-10,000$ & $68(16.7)$ \\
\hline$>10,000$ & $58(14.3)$ \\
\hline
\end{tabular}

\section{Reliability and Validity Test}

This study used Cronbach $\alpha$ to measure the reliability of the questionnaire. The lowest value of Cronbach $\alpha$ for this questionnaire was .764 and the highest value was .900, indicating that the measurement scale had good reliability. In order to test the discriminant validity of variables in the model, we used SPSS Amos, version 24.0, to conduct confirmatory factor analysis on performance expectation, effort expectation,

social impact, perceived risk, contributing factors, and willingness to use the platform. The indicators were as follows: adjusted goodness-of-fit index $(\mathrm{AGFI})=0.858$, goodness-of - fit index $(\mathrm{GFI})=0.893$, comparative fit index $(\mathrm{CFI})=0.935$, root mean square error of approximation (RMSEA) $=0.063$, composite reliability $(\mathrm{CR})>0.7$, and average variance extracted (AVE) $>0.5$. It can be seen that the goodness of fit of the model was good; that is, the variables had good discriminant validity (see Tables 3 and 4). 
Table 3. Results of the questionnaire reliability analysis.

\begin{tabular}{|c|c|c|c|c|c|c|c|}
\hline $\begin{array}{l}\text { Dimension and item number } \\
\text { Performance expectancy (PE) }\end{array}$ & \multicolumn{4}{|c|}{ Correlation matrix between items } & $\begin{array}{l}\text { Corrected item's total } \\
\text { correlation }\end{array}$ & $\begin{array}{l}\text { Cronbach } \alpha \text { if item } \\
\text { deleted }\end{array}$ & $\begin{array}{l}\text { Cronbach } \alpha \text { of the } \\
\text { dimension }\end{array}$ \\
\hline PE.1 & 1 & & & & 0.538 & .895 & $\mathrm{~N} / \mathrm{A}^{\mathrm{a}}$ \\
\hline PE. 2 & 0.715 & 1 & & & 0.647 & .893 & N/A \\
\hline PE. 3 & 0.413 & 0.448 & 1 & & 0.452 & .898 & N/A \\
\hline PE.4 & 0.403 & 0.489 & 0.614 & 1 & 0.598 & .894 & N/A \\
\hline Effort expectancy (EE) & & & & & & & .764 \\
\hline EE.1 & 1 & & & & 0.690 & .891 & N/A \\
\hline EE.2 & 0.576 & 1 & & & 0.673 & .892 & N/A \\
\hline Social influence (SI) & & & & & & & .802 \\
\hline SI.1 & 1 & & & & 0.550 & .895 & N/A \\
\hline SI.2 & 0.629 & 1 & & & 0.572 & .894 & N/A \\
\hline SI.3 & 0.566 & 0.660 & 1 & & 0.502 & .896 & N/A \\
\hline SI.4 & 0.415 & 0.429 & 0.382 & 1 & 0.699 & .891 & N/A \\
\hline Facilitating conditions (FC) & & & & & & & .875 \\
\hline FC. 1 & 1 & & & & 0.701 & .891 & N/A \\
\hline FC. 2 & 0.638 & 1 & & & 0.663 & .892 & N/A \\
\hline FC. 3 & 0.581 & 0.659 & 1 & & 0.651 & .893 & N/A \\
\hline FC. 4 & 0.630 & 0.586 & 0.727 & 1 & 0.675 & .892 & N/A \\
\hline Perceived risk (PR) & & & & & & & .841 \\
\hline PR.1 & 1 & & & & 0.234 & .903 & N/A \\
\hline PR.2 & 0.600 & 1 & & & 0.225 & .904 & N/A \\
\hline PR.3 & 0.525 & 0.633 & 1 & & 0.227 & .904 & N/A \\
\hline PR.4 & 0.473 & 0.558 & 0.646 & 1 & 0.140 & .909 & N/A \\
\hline Behavioral intention (BI) & & & & & & & .879 \\
\hline BI.1 & 1 & & & & 0.666 & .892 & N/A \\
\hline BI.2 & 0.662 & 1 & & & 0.631 & .893 & N/A \\
\hline BI.3 & 0.629 & 0.734 & 1 & & 0.625 & .893 & N/A \\
\hline Total scale & & & & & & & .900 \\
\hline
\end{tabular}

${ }^{\mathrm{a}} \mathrm{N} / \mathrm{A}$ : not applicable; Cronbach $\alpha$ in this column was calculated for each dimension, not for each item. 
Table 4. Results of the questionnaire validity analysis.

\begin{tabular}{|c|c|c|c|}
\hline Dimension and item number & Standardized factor load & Composite reliability & Average variance extracted ${ }^{\mathrm{a}}$ \\
\hline Performance expectancy (PE) & & & 0.693 \\
\hline PE.1 & 0.684 & 0.899 & $\mathrm{~N} / \mathrm{A}^{\mathrm{b}}$ \\
\hline PE. 2 & 0.832 & & N/A \\
\hline PE.3 & 0.933 & & N/A \\
\hline PE.4 & 0.862 & & N/A \\
\hline Effort expectancy (EE) & & & 0.522 \\
\hline EE.1 & 0.625 & 0.710 & N/A \\
\hline EE.2 & 0.695 & & N/A \\
\hline Social influence (SI) & & & 0.681 \\
\hline SI.1 & 0.868 & 0.864 & N/A \\
\hline SI.2 & 0.845 & & N/A \\
\hline SI.3 & 0.758 & & N/A \\
\hline Perceived risk (PR) & & & 0.550 \\
\hline PR.1 & 0.867 & 0.826 & N/A \\
\hline PR.2 & 0.804 & & N/A \\
\hline PR.3 & 0.541 & & N/A \\
\hline PR.4 & 0.714 & & N/A \\
\hline Facilitating conditions (FC) & & & 0.617 \\
\hline FC.1 & 0.780 & 0.828 & N/A \\
\hline FC. 2 & 0.695 & & N/A \\
\hline FC. 3 & 0.872 & & N/A \\
\hline Behavioral intention (BI) & & & 0.567 \\
\hline BI.1 & 0.568 & 0.793 & N/A \\
\hline BI.2 & 0.829 & & N/A \\
\hline BI.3 & 0.831 & & N/A \\
\hline
\end{tabular}

${ }^{\mathrm{a}}$ The fitting indices were as follows: $\chi^{2} / \mathrm{df}=2.1$, adjusted goodness-of-fit index (AGFI) $=0.858$, goodness-of-fit index $(\mathrm{GFI})=0.893$, comparative fit index $(\mathrm{CFI})=0.935$, and root mean square error of approximation $(\mathrm{RMSEA})=0.063$.

${ }^{\mathrm{b}} \mathrm{N} / \mathrm{A}$ : not applicable; average variance extracted was calculated for each dimension, not for each item.

\section{Structural Equation Model Verification}

Structural equation modeling is a statistical method used to analyze the relationship between variables. According to the degree of consistency between the theoretical model and the actual data, the theoretical model is evaluated to achieve the goals of quantitative research on actual problems. This method overcomes the shortcomings of SPSS software's widely used multiple regression analysis method. It not only explains the relationship between variables but also allows the existence of measurement error of the variables. It can realize the estimation of factor structure and relationship as well as the simultaneous estimation of the degree of model fitting. In this study, the structural equation model analysis software SPSS Amos, version 24.0, was used to draw the structural equation model analysis diagram (see Figure 1); the model verification of the parameters of the initial hypothetical model was carried out to analyze the relationship between the variables and their influence mechanisms (see Table 5). From the significance of the model path coefficient, it can be seen that Hypothesis 1, Hypothesis 2, and Hypothesis 5 are valid, while the assumptions of Hypothesis 3 and Hypothesis 4 are not valid. That is to say, performance expectation, effort expectation, and contributing factors have significant effects on patients' willingness to use mobile medical services. However, social influence and perceived risk do not have significant effects on patients' willingness to use mobile medical services. In order to ensure the rigor of the model's logic, the two insignificant paths mentioned above were deleted, the revised model was obtained, and the SPSS Amos, version 24.0, program was run again to verify each parameter. The corrected significance level of each path coefficient was less than 0.001, and the model-fitting indexes were as follows: $\chi^{2} / \mathrm{df}=3.5, \mathrm{CFI}=0.899$, AGFI $=0.900$, and $\mathrm{RMSEA}=0.092$. These values indicate that the revised model fit was acceptable. 
According to the estimation result of the model path coefficient and the analysis result of the adjustment effect, we finally determined the following: performance expectation, effort expectation, and contributing factors are the three main factors influencing patients' use of online hospitals and they play a positive role.

Figure 1. Results of the structural equation model analysis. Note, e1 to e31 are residuals, which are not explained in the hypothesis equation. The number on each arrow indicates the factor load of the latent variable on the observed variable: the larger the factor load, the better. If the value is greater than .40 and less than 1 , the contribution is qualified.

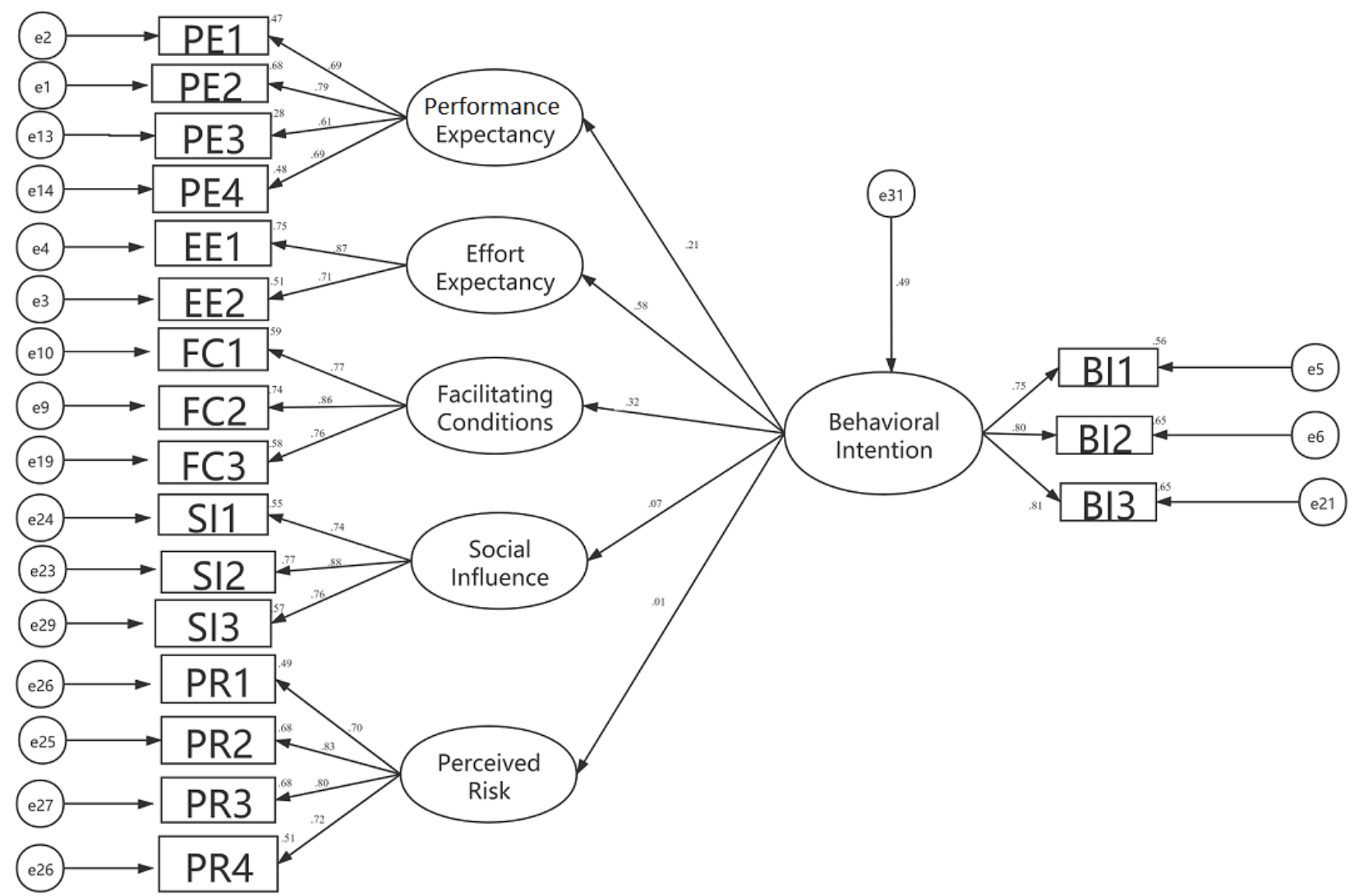

Table 5. Verification of the path coefficients of the initial hypothesis model.

\begin{tabular}{|c|c|c|c|c|c|c|}
\hline Hypothesis $(\mathrm{H})$ & Path & Estimate & SE & Composite reliability & $P$ value & Results \\
\hline $\mathrm{H} 1$ & $\mathrm{PE}^{\mathrm{a}} \rightarrow \mathrm{BI}^{\mathrm{b}}$ & 0.21 & 0.063 & 2.587 & .01 & Established \\
\hline $\mathrm{H} 2$ & $\mathrm{EE}^{\mathrm{c}} \rightarrow \mathrm{BI}$ & 0.58 & 0.076 & 6.290 & $<.001$ & Established \\
\hline $\mathrm{H} 3$ & $\mathrm{SI}^{\mathrm{d}} \rightarrow \mathrm{BI}$ & 0.07 & 0.045 & 1.217 & .22 & Not established \\
\hline $\mathrm{H} 4$ & $\mathrm{PR}^{\mathrm{e}} \rightarrow \mathrm{BI}$ & 0.01 & 0.031 & 0.286 & .78 & Not established \\
\hline H5 & $\mathrm{FC}^{\mathrm{f}} \rightarrow \mathrm{BI}$ & 0.32 & 0.055 & 4.414 & $<.001$ & Established \\
\hline
\end{tabular}

${ }^{\mathrm{a}} \mathrm{PE}$ : performance expectancy.

${ }^{\mathrm{b}} \mathrm{BI}$ : behavioral intention.

${ }^{\mathrm{c}} \mathrm{EE}$ : effort expectancy.

${ }^{\mathrm{d}} \mathrm{SI}$ : social influence.

${ }^{\mathrm{e}} \mathrm{PR}$ : perceived risk.

${ }^{\mathrm{f}} \mathrm{FC}$ : facilitating conditions.

\section{The Relationship Between Different Demographic Characteristics and Willingness to Use Online Hospitals}

Structural equation modeling and hypothesis tests were applied in this research. A $P$ value less than .05 is considered statistically significant. To measure the relationship between gender, age, education level, income, and willingness to use online hospitals, we conducted a separate test by establishing a logistic regression model, and the result is summarized in Table 6. Here, we took male gender and less than high school education level as the reference group and transformed behavioral intention into a 
binary variable (0: reject; 1 : accept). We found that gender $(P=.048)$ and education level $(P=.04)$ affected the willingness to use online hospitals, and both of them promoted the use of online hospitals (odds ratio [OR] 2.844, 95\% CI 1.010-8.003, and OR $2.187,95 \%$ CI 1.031-4.636, respectively) as shown in
Table 6. In other words, female participants' willingness to use online hospitals was 2.844 times that of male participants, while willingness to use online hospitals increased 2.187 times (ie, OR $2.187,95 \%$ CI 1.031-4.636) with each level of education.

Table 6. Variables in the equation.

\begin{tabular}{llllll}
\hline Variable & $\mathrm{B}$ & $\mathrm{SE}$ & Wald value & $P$ value & Odds ratio (95\% CI) \\
\hline Gender & 1.045 & 0.528 & 3.918 & .048 & $2.844(1.010-8.003)$ \\
Age & -0.262 & 0.444 & 0.349 & .56 & $0.769(0.323-1.836)$ \\
Education & 0.782 & 0.383 & 4.162 & .04 & $2.187(1.031-4.636)$ \\
Income & -0.128 & 0.219 & 0.343 & .56 & $0.880(0.573-1.351)$ \\
\hline
\end{tabular}

\section{Discussion}

\section{Principal Findings}

A total of 407 young and middle-aged patients at a hospital in Western China were surveyed regarding their willingness to use an online hospital. This study analyzed the factors, and their relationships, that influenced patients' use of online hospitals and provided some prior information and a theoretical basis upon which other researchers can carry out similar research. The results show that the public's awareness and usage of online hospitals was low. According to the estimation results of the model path coefficient and the analysis of the adjustment effect, we determined the following: performance expectancy, effort expectancy, and facilitating conditions were the three main factors that affected patients' willingness to use an online hospital. They all had a positive impact on behavioral intention. It can also be seen from the path coefficient results in Table 5 that effort expectancy is the most important factor. This may indicate that the user's effort expectancy shows the user's ability to accept new things to a certain extent. When users encounter unfamiliar content when operating within the online hospital platform, their efforts will inspire them to try and learn new things, so as to make better use of online hospitals. From Table 5 , we can see that performance expectancy had a positive impact on behavioral intention, which shows that perceived ease of use of mobile medical platforms and the usefulness of mobile medical services may have a positive effect on patients' willingness to use online hospitals [28]. Furthermore, facilitating conditions also had a positive impact on behavioral intention, which shows that some external promotion effects, such as medical staff recommendations and guidance, government policy support, and policies that benefit people, will probably increase the willingness of patients to use online hospital mobile medical services. In addition, gender and education level were personal factors that influenced patients' willingness to use mobile medical services. It can be seen from the OR value in Table 6 that women were more likely to accept mobile medical services of online hospitals than were men; the acceptability by women was 2.844 times that of men. Meanwhile, the higher the education level that a patient had, the more adventurous the patient became. The acceptance increased 2.187 times with each increase in education level. People with higher education levels may be more willing to try this new type of technology platform. Throughout the whole process, it was indicated that certain patient attributes may influence people's decisions. Further research is needed to explore these relationships more deeply.

\section{Research Impact}

The current outbreak of COVID-19 is still spreading all over the world, which poses great threats to the safety and health of people around the world. Medical systems in all countries are facing great amounts of pressure and challenges. This study has several implications for both researchers and practitioners of mobile medicine and provides a reference for the response to the COVID-19 pandemic. Online hospitals constitute a new mode of telemedicine. Members of the public are limited by traditional modes of medical thinking and their awareness is relatively low. Most of them hold a conservative wait-and-see attitude. There will be a certain resistance to this in the early stages. Medical habits and thinking styles require a transformation process [29]. To change the public's resistance to change, the government and medical institutions need to continue to increase the promotion of mobile medical services. It will be important to pay attention to improving public eHealth literacy [30], especially among middle-aged and elderly groups who know little about new technologies and have relatively low levels of education. Differentiated promotion in different age groups will be important, focusing on the interaction between patient groups. At the same time, it is necessary to fully standardize the management of mobile medical practitioners; strictly control the quality of mobile medical services; conduct daily monitoring and scoring of doctors' qualification reviews, prejob training, medical quality, service attitudes, and patient satisfaction; and establish multidimensional online assessment standards and scientific management of every aspect of mobile medical service. In this regard, government departments should play a leading role. We can learn from the experience of developed countries with regard to the supervision of mobile medical services $[31,32]$. It will be important to accelerate the improvement of relevant legislation and regulatory policies and to formulate mobile medical service quality standards, industry regulations, and information security standards in order to promote the long-term development of online hospitals.

\section{Research Limitations}

Since this study recruited a cross-sectional sample of young and middle-aged participants in Western China, it may not truly reflect the willingness of the entire Chinese population or groups in other regions to adopt mobile medical services. In addition, 
this study found that social influence and perceived risk have no significant impact on patients' willingness to use online hospitals. This is inconsistent with the results of other studies on the willingness to adopt other mobile health technologies. Further research is needed to re-examine social influence and perceived risk. At the same time, mobile medical services are under continuous development in China, and the relevant research has not yet formed a relatively complete research framework.

\section{Acknowledgments}

This research was supported by the 1.3.5 Project for Disciplines of Excellence of West China Hospital, Sichuan University (grant No. ZYJC18042).

\section{Conflicts of Interest}

None declared.

\section{Multimedia Appendix 1}

Measurement items of research variables.

[DOCX File, 14 KB-Multimedia Appendix 1]

\section{References}

1. Alam MZ, Hoque MR, Hu W, Barua Z. Factors influencing the adoption of mHealth services in a developing country: A patient-centric study. Int J Inf Manage 2020 Feb;50:128-143. [doi: 10.1016/j.ijinfomgt.2019.04.016]

2. Han Y, Lie RK, Guo R. The internet hospital as a telehealth model in China: Systematic search and content analysis. J Med Internet Res 2020 Jul 29;22(7):e17995 [FREE Full text] [doi: 10.2196/17995] [Medline: 32723721]

3. Bürmann Genannt Siggemann C, Mensing M, Classen T, Hornberg C, Terschüren C. Specific health status has an impact on the willingness to use telemonitoring: Data from a 2009 health survey in North Rhine-Westphalia, Germany. Telemed J E Health 2013 Sep;19(9):692-698. [doi: 10.1089/tmj.2012.0214] [Medline: 23906307]

4. Yang X, Song B, Wu A, Mo PKH, Di JL, Wang Q, et al. Social, cognitive, and eHealth mechanisms of COVID-19-related lockdown and mandatory quarantine that potentially affect the mental health of pregnant women in China: Cross-sectional survey study. J Med Internet Res 2021 Jan 22;23(1):e24495 [FREE Full text] [doi: 10.2196/24495] [Medline: 33302251]

5. Wei Y, Zheng P, Deng H, Wang X, Li X, Fu H. Design features for improving mobile health intervention user engagement: Systematic review and thematic analysis. J Med Internet Res 2020 Dec 09;22(12):e21687 [FREE Full text] [doi: 10.2196/21687] [Medline: 33295292]

6. Tavares J, Oliveira T. Electronic health record portal adoption: A cross country analysis. BMC Med Inform Decis Mak 2017 Jul 05;17(1):97 [FREE Full text] [doi: 10.1186/s12911-017-0482-9] [Medline: 28679423]

7. Venkatesh V, Morris MG, Davis GB, Davis FD. User acceptance of information technology: Toward a unified view. MIS Q 2003;27(3):425. [doi: 10.2307/30036540]

8. Bawack RE, Kala Kamdjoug JR. Adequacy of UTAUT in clinician adoption of health information systems in developing countries: The case of Cameroon. Int J Med Inform 2018 Jan;109:15-22. [doi: 10.1016/j.ijmedinf.2017.10.016] [Medline: 29195701]

9. Alsharo M, Alnsour Y, Alabdallah M. How habit affects continuous use: Evidence from Jordan's national health information system. Inform Health Soc Care 2020 Jan;45(1):43-56. [doi: 10.1080/17538157.2018.1540423] [Medline: $\underline{30457025]}$

10. Ward R. The application of technology acceptance and diffusion of innovation models in healthcare informatics. Health Policy Technol 2013 Dec;2(4):222-228. [doi: 10.1016/j.hlpt.2013.07.002]

11. Phichitchaisopa N, Naenna T. Factors affecting the adoption of healthcare information technology. EXCLI J 2013;12:413-436 [FREE Full text] [Medline: 26417235]

12. Cimperman M, Makovec Brenčič M, Trkman P. Analyzing older users' home telehealth services acceptance behavior-applying an extended UTAUT model. Int J Med Inform 2016 Jun;90:22-31. [doi: 10.1016/j.ijmedinf.2016.03.002] [Medline: 27103194]

13. McConnell MV, Turakhia MP, Harrington RA, King AC, Ashley EA. Mobile health advances in physical activity, fitness, and atrial fibrillation: Moving hearts. J Am Coll Cardiol 2018 Jun 12;71(23):2691-2701 [FREE Full text] [doi: 10.1016/j.jacc.2018.04.030] [Medline: 29880130]

14. McKay FH, Cheng C, Wright A, Shill J, Stephens H, Uccellini M. Evaluating mobile phone applications for health behaviour change: A systematic review. J Telemed Telecare 2018 Jan;24(1):22-30. [doi: 10.1177/1357633X16673538] [Medline: 27760883]

15. Deng Z. Understanding public users' adoption of mobile health service. Int J Mob Commun 2013;11(4):351. [doi: 10.1504/IJMC.2013.055748]

16. Signal V, McLeod M, Stanley J, Stairmand J, Sukumaran N, Thompson D, et al. A mobile- and web-based health intervention program for diabetes and prediabetes self-management (BetaMe/Melon): Process evaluation following a randomized controlled trial. J Med Internet Res 2020 Dec 01;22(12):e19150 [FREE Full text] [doi: 10.2196/19150] [Medline: 33258776] 
17. Kumar S, Nilsen WJ, Abernethy A, Atienza A, Patrick K, Pavel M, et al. Mobile health technology evaluation: The mHealth evidence workshop. Am J Prev Med 2013 Aug;45(2):228-236 [FREE Full text] [doi: 10.1016/j.amepre.2013.03.017] [Medline: 23867031]

18. Venkatesh V, Brown SA, Maruping LM, Bala H. Predicting different conceptualizations of system use: The competing roles of behavioral intention, facilitating conditions, and behavioral expectation. MIS Q 2008;32(3):483. [doi: 10.2307/25148853]

19. Hoque R, Sorwar G. Understanding factors influencing the adoption of mHealth by the elderly: An extension of the UTAUT model. Int J Med Inform 2017 May;101:75-84. [doi: 10.1016/j.ijmedinf.2017.02.002] [Medline: 28347450]

20. Hoque MR, Bao Y, Sorwar G. Investigating factors influencing the adoption of e-Health in developing countries: A patient's perspective. Inform Health Soc Care 2017 Jan;42(1):1-17. [doi: 10.3109/17538157.2015.1075541] [Medline: 26865037]

21. Xue L, Yen CC, Chang L, Chan HC, Tai BC, Tan SB, et al. An exploratory study of ageing women's perception on access to health informatics via a mobile phone-based intervention. Int J Med Inform 2012 Sep;81(9):637-648. [doi: 10.1016/j.ijmedinf.2012.04.008] [Medline: 22658778]

22. Alalwan AA, Dwivedi YK, Rana NP. Factors influencing adoption of mobile banking by Jordanian bank customers: Extending UTAUT2 with trust. Int J Inf Manage 2017 Jun;37(3):99-110. [doi: 10.1016/j.ijinfomgt.2017.01.002]

23. Shareef MA, Kumar V, Kumar U. Predicting mobile health adoption behaviour: A demand side perspective. J Customer Behav 2014 Oct 31;13(3):187-205. [doi: 10.1362/147539214x14103453768697]

24. Nguyen AD, Frensham LJ, Baysari MT, Carland JE, Day RO. Patients' use of mobile health applications: What general practitioners think. Fam Pract 2019 Mar 20;36(2):214-218. [doi: 10.1093/fampra/cmy052] [Medline: 29873708]

25. Kim J, Park H. Development of a health information technology acceptance model using consumers' health behavior intention. J Med Internet Res 2012 Oct 01;14(5):e133 [FREE Full text] [doi: 10.2196/jmir.2143] [Medline: 23026508]

26. Hsieh P. Healthcare professionals' use of health clouds: Integrating technology acceptance and status quo bias perspectives. Int J Med Inform 2015 Jul;84(7):512-523. [doi: 10.1016/j.ijmedinf.2015.03.004] [Medline: 25842155]

27. Cilliers L, Viljoen KL, Chinyamurindi WT. A study on students' acceptance of mobile phone use to seek health information in South Africa. Health Inf Manag 2018 May;47(2):59-69. [doi: 10.1177/1833358317706185] [Medline: 28537211]

28. Willard S, van Rossum E, Spreeuwenberg M, de Witte L. Perceived impact of an online community care platform for Dutch older adults on local participation, informal caregiving, and feelings of connectedness: Pretest-posttest observational study. J Med Internet Res 2020 Dec 01;22(12):e20304 [FREE Full text] [doi: 10.2196/20304] [Medline: 33258779]

29. Royston G, Hagar C, Long L, McMahon D, Pakenham-Walsh N, Wadhwani N, mHIFA Working Group (Mobile Healthcare Information For All). Mobile health-care information for all: A global challenge. Lancet Glob Health 2015 Jul;3(7):e356-e357 [FREE Full text] [doi: 10.1016/S2214-109X(15)00054-6] [Medline: 26087979]

30. Mukred A, Singh D, Safie N. Investigating the impact of information culture on the adoption of information system in public health sector of developing countries. Int J Bus Inf Syst 2017;24(3):261. [doi: 10.1504/ijbis.2017.082036]

31. Iwaya LH, Gomes MAL, Simplício MA, Carvalho TCMB, Dominicini CK, Sakuragui RRM, et al. Mobile health in emerging countries: A survey of research initiatives in Brazil. Int J Med Inform 2013 May;82(5):283-298. [doi: 10.1016/j.ijmedinf.2013.01.003] [Medline: 23410658]

32. Shuren J, Patel B, Gottlieb S. FDA regulation of mobile medical apps. JAMA 2018 Jul 24;320(4):337-338. [doi: 10.1001/jama.2018.8832] [Medline: 29971339]

\section{Abbreviations}

AGFI: adjusted goodness-of-fit index

AVE: average variance extracted

CFI: comparative fit index

CR: composite reliability

GFI: goodness-of-fit index

IT: information technology

OR: odds ratio

RMSEA: root mean square error of approximation

UTAUT: Unified Theory of Acceptance and Use of Technology 
Edited by G Eysenbach; submitted 22.11.20; peer-reviewed by X Zhang, C Carrion; comments to author 11.12.20; revised version received 27.12.20; accepted 13.01.21; published 05.02.21

Please cite as:

Wang $\mathrm{H}$, Liang $L, D u C$, Wu $Y$

Implementation of Online Hospitals and Factors Influencing the Adoption of Mobile Medical Services in China: Cross-Sectional Survey Study

JMIR Mhealth Uhealth 2021;9(2):e25960

URL: http://mhealth.jmir.org/2021/2/e25960/

doi: $\underline{10.2196 / 25960}$

PMID: $\underline{3444155}$

(CHuanlin Wang, LanYu Liang, ChunLin Du, YongKang Wu. Originally published in JMIR mHealth and uHealth (http://mhealth.jmir.org), 05.02.2021. This is an open-access article distributed under the terms of the Creative Commons Attribution License (https://creativecommons.org/licenses/by/4.0/), which permits unrestricted use, distribution, and reproduction in any medium, provided the original work, first published in JMIR mHealth and uHealth, is properly cited. The complete bibliographic information, a link to the original publication on http://mhealth.jmir.org/, as well as this copyright and license information must be included. 